\title{
THE MEASURED EFFECT OF LAPAROTOMY ON THE RESPIRATION
}

\author{
BY HENRY K. BEECHER 1 \\ (From the Surgical Services and Metabolism Laboratory of the Massachusetts \\ General Hospital, Boston)
}

(Received for publication January 16, 1933)

In the past, many attempts $(1,2,3,4,5,6,7,8,9,10)$ have been made to discover the origin of postoperative pulmonary complications. Nearly all of these attempts have been concerned with the study and analysis of hospital records. The results of this method of study have been disappointing. In the present research, the question has been analyzed from a new angle. The aim has been to measure quantitatively the effect of laparotomy on the respiration. It was found possible to do this with considerable accuracy.

The study made is of the environment in which complications develop, rather than of the complications themselves. The problem is complex. In order to keep it as simple as possible, the combined effect of laparotomy with its attendant circumstances was studied. "Laparotomy" as used includes the following associated procedures as being part of the operationrest in bed, tight bandaging, postoperative medication. To group them in this way does not mean that these factors are not individually important; they are, and they should be studied separately, as soon as it is possible to do so. It has seemed best, however, to investigate first the combined effect of the laparotomy with all the procedures which accompany it, to concentrate on this combined effect, rather than to spread the effort thinly over a variety of problems.

A Benedict-Roth ${ }^{2}$ spirometer with rubber mouthpiece, nose clip, recording pen and drum was used, of the type commonly employed in making measurements of the basal metabolism. Patients were placed in bed in a position as nearly as possible like that which they occupy after operation. They breathed into the spirometer for seven minutes, a tracing was recorded, and the following information was obtained.

Respiratory rate: from an average of the rates of three alternate minutes over the seven minute period.

1 During the two years in which the bulk of this work was done the writer was the holder of the James Jackson Cabot Fellowship of Harvard University. This study and the one to follow were awarded the Warren Triennial Prize of the Massachusetts General Hospital for 1931.

2 Warren Collins Co., Boston. 
Tidal air (average-size breath): from an average of twenty equally spaced breaths over the seven minute period.

Total ventilation (minute volume): from the product of the average volume of tidal air and the average respiratory rate.

Vital capacity: volume of a maximal expiration, made following a maximal inspiration.

Complemental air: that volume of the vital capacity which is above the average tidal air; i.e., above the average inspiratory line.

Supplemental air: that volume of the vital capacity which is below the average tidal air, below the average expiratory line.

These terms are made clearer in a diagram, Figure 1.

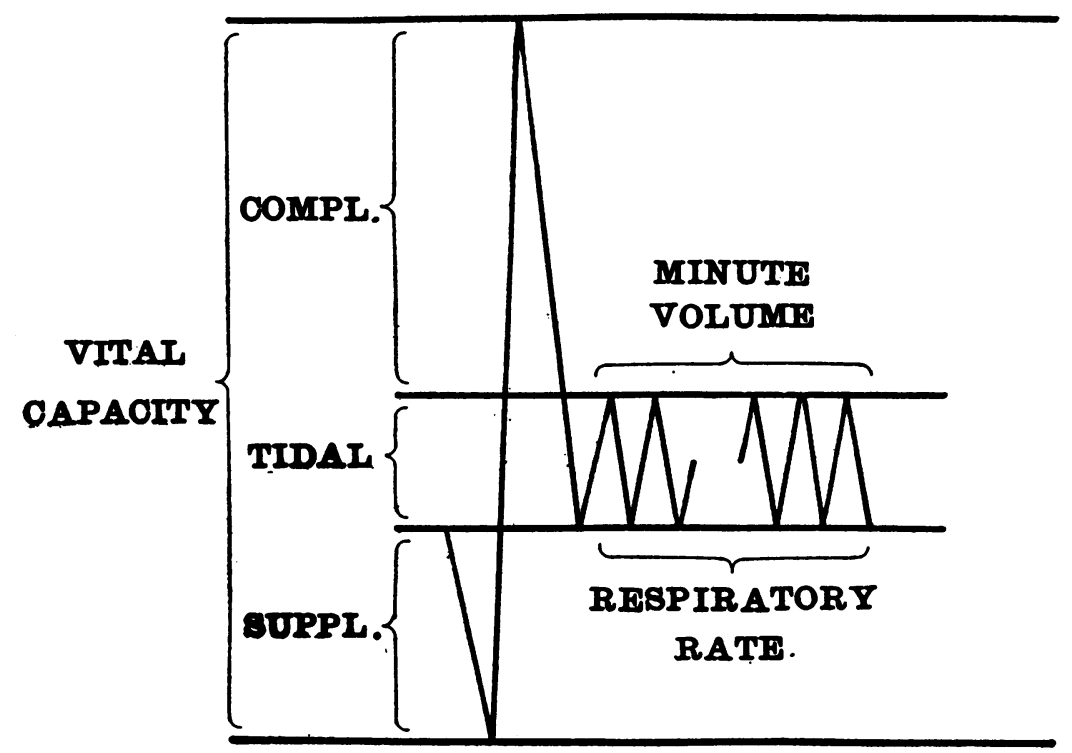

Fig. 1. Normal Respiratory Volumes in a Recumbent Patient

General information obtained in each case included sex, age, height, weight, diagnosis, anesthetic (kind, duration), operation, as well as the time, daily temperature, pulse rate and blood pressure, medication, and anything unusual in the patient's condition.

The data were obtained simultaneously, one to three times preceding operation and then from day to day afterwards. In case only one preoperative study was made, in establishing the normal, that one was considered together with the last study following recovery. An attempt was made to obtain data postoperatively on the first, second, third, fifth, seventh, tenth and fourteenth days. For various reasons, regularity was not always possible; at other times it was possible to obtain a more complete set of data. Since pulmonary complications usually occur within the first five days after operation, this period was studied the most intensively. After completion 
of a case study the data were recalculated in terms of percentage of the preoperative value. The preoperative values were rated one hundred per cent. This has no reference to a theoretical or calculated one hundred per cent value. These data were then plotted so that current trends could be more easily appreciated, postoperative value being expressed as per cent of the preoperative.

Cases studied. ${ }^{3}$ The cases of sixty-four patients were studied before and after laparotomy. Investigation of many cases was started but never completed because the patients were not operated upon or were too ill subsequently to be studied in even the gentlest fashion, or because death intervened. Only one case was lost because of failure of the patient to cooperate. The failure of only one patient to cooperate out of nearly one hundred worked upon, demonstrates the fact that patients were not greatly inconvenienced by the tests, though some were so weak it was necessary to hold their lips around the rubber mouthpiece.

Certain points were considered in grouping the results. It is well known that the incidence of postoperative pulmonary complications is much higher in men than in women. Three to one is the figure usually given $(4,5,9,11)$. It is higher also after upper (above the umbilicus) than lower abdominal operations $(3,4,8,9)$. The ideal arrangement would be to study the effect of each operation separately, but because of the difficulty of obtaining enough cases of a given operation and because complications fall fairly well into four groups, it was thought that four larger series of data corresponding to the four distinct groups of complication rates were desirable, rather than more numerous but smaller series. Accordingly four divisions of the data were made: upper and lower abdominal operations in men and in women.

In women, there were 18 upper abdominal operations consisting of 14 cholecystectomies, 1 duodenal and 3 gastric operations; and 22 lower abdominal operations, comprising 2 uterine suspensions, 1 exploratory laparotomy with salpingectomy, 2 supravaginal hysterectomies, 5 supravaginal hysterectomies with appendectomies, 1 appendectomy, and 11 exploratory laparotomies with appendectomies.

In men, there were included 11 upper abdominal operations consisting of 1 nephrectomy (anterior incision), 2 exploratory laparotomies, and 8 gastric operations; and 13 lower abdominal operations including 1 appendectomy, 1 cecostomy, 2 colostomies, 2 exploratory laparotomies, and 7 hernia repairs.

8 Thirteen of the sixty-four cases studied showed postoperative pulmonary complications. Five of these complications were diagnosed as bronchitis, five as moderate collapse, three as bronchopneumonia. It was thought that the thirteen cases in which the complications occurred did not form an adequate series for the study of the effect of postoperative pulmonary complications on the respiration. These data on the thirteen cases will be held in reserve until a larger series can be obtained. 
More than 4000 measurements were obtained. The pulmonary volumes were corrected to $0^{\circ} \mathrm{C}$. and $760 \mathrm{~mm}$. $\mathrm{Hg}$ pressure. Due to the large number, only average figures are presented in graphic form. The significance of data has been indicated by calculating the standard error of the mean, $S E_{M}=\left(\sqrt{\Sigma D^{2}} / N\right)$, at two points, the control (preoperative) point and the point showing maximum deviation from the preoperative.

In order to simplify the curves, the data were combined in the following manner: all values obtained on the first day after upper abdominal operations, for example in men, were averaged; likewise those obtained on the second, on the third and fourth days, all values on the fifth, sixth, and seventh days, on the eighth, ninth, and tenth days and finally on the eleventh, twelfth, thirteenth and fourteenth days. A table will show this simply.

\begin{tabular}{c|c|c|c|c|c|c|c|c}
\hline \hline Days postoperatively...................... & 1 & 2 & 3,4 & $5,6,7$ & $8,9,10$ & $11,12,13,14$ \\
\hline Period postoperatively........... & 1 & 2 & 4 & 6 & 9 & 12 \\
\hline
\end{tabular}

Since analyses of the respiration were made more frequently during the first five days postoperatively and less frequently thereafter, this grouping of points gives more equal weight to each point than if the average value were plotted each day. Each point represents an equal number of measurements.

Since the differences following upper and following lower abdominal operations in men and in women were less than had been anticipated, only curves of composite data will be presented. Where marked differences in the four groups occurred, the facts will be noted. In presenting data of this sort it has seemed better to avoid any theoretical discussion as to the significance in regard to the postoperative pulmonary complications; consequently, the following data are offered with only the briefest comments.

Figure 2 is based on 1472 determinations. It is a composite of the data obtained. It demonstrates quantitatively a fact which has long been recognized: there is rapid, shallow respiration postoperatively. The graph shows the reduction of the tidal air $(T V)$ by laparotomy. An average 20 per cent reduction occurred on the first day postoperatively and was accompanied by a simultaneous rise of 26 per cent in the respiratory rate $(R R)$. It is interesting to observe, particularly during the first eight days postoperatively, that the curve representing the respiratory rate and that of the tidal air are practically superimposable, the one being the inverse picture of the other.

Further analyzing the data obtained, it was found that from the second postoperative day, upper abdominal operations in men resulted in an 11 per cent greater reduction in tidal air than did lower abdominal operations; this greater crippling was maintained through the twelfth day. In females an 
insignificant difference of 3 per cent was found. Inasmuch as upper abdominal operations in men are most frequently followed by pulmonary complications, it is interesting to observe that the most severe reduction in tidal air occurs in men and persists for the longest time. Furthermore, this greatest reduction occurs not on the first, but on the second day after operation.

Since, for brevity, actual values are not given, it is necessary to furnish proof that the rise of respiratory rate and the fall in tidal air are statistically

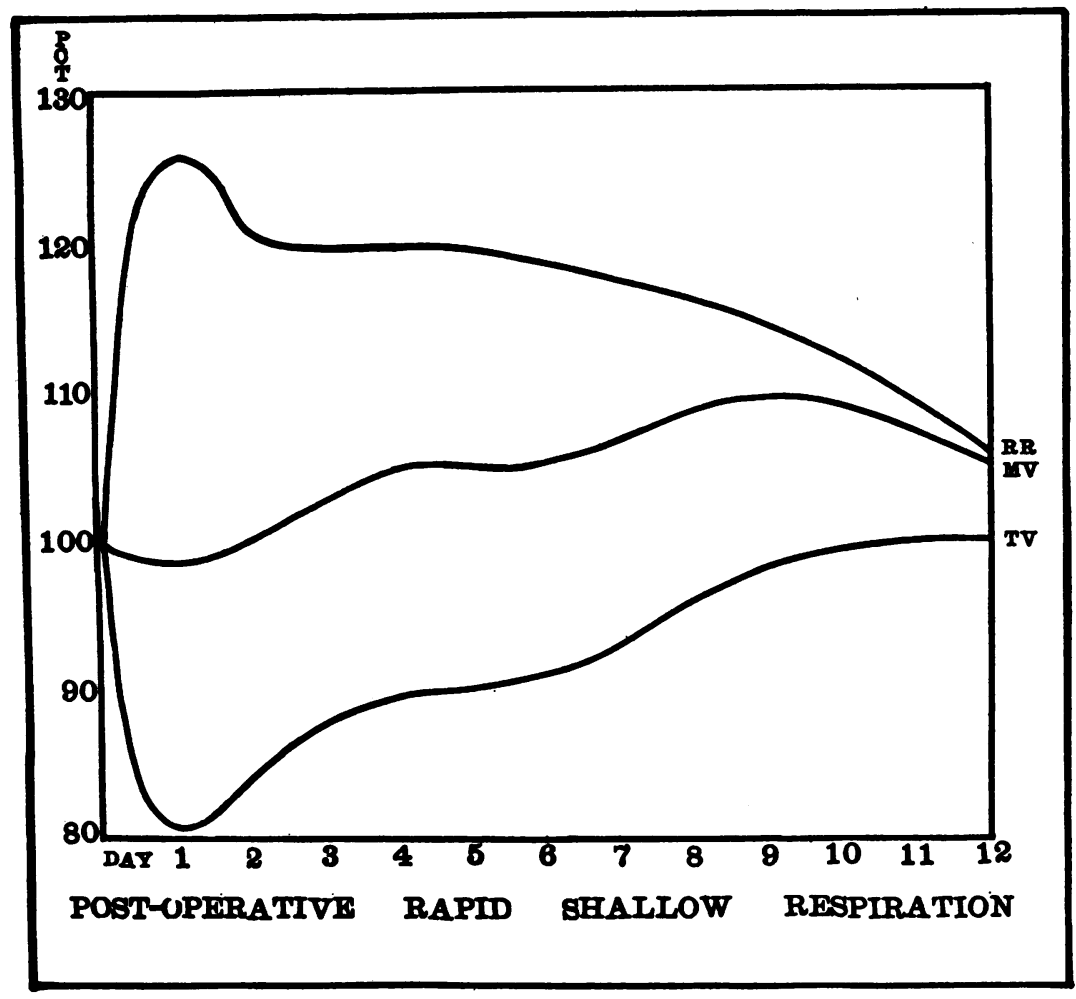

Fig. 2

$R R=$ Respiratory rate

$M V=$ Minute volume

$T V=$ Tidal volume

Abscissa $=$ Days postoperative

Ordinate $=$ Postoperative per cent of preoperative values

significant. This can be done mathematically. The standard error for the average preoperative respiratory rate is 0.62 respiration per minute. On the first day after operation, when the rate showed an average rise of 26 per cent, the standard error is 0.81 respiration per minute. The difference between the actual rates at the two points is expressed by $4.25 \pm 1.02$ 
respirations per minute. (To be statistically significant, we have assumed that the difference, 4.25 , must be more than twice its standard error, 1.02.) The rise in respiratory rate is unquestionably significant. That the decrease in tidal air is real, is apparent from the following. The standard error of the preoperative control period is $23.6 \mathrm{cc}$. On the first day after the operation when the tidal air fell 20 per cent the standard error of the point is $19.4 \mathrm{cc}$. The difference between the actual averages of the two points is $138 \pm 30.6 \mathrm{cc}$. which is 4.5 times its standard error. The decrease in tidal air is therefore significant.

The curve $M V$ in Figure 2 demonstrates the change in the mean of minute volume of air breathed. Though there is an apparent gradual increase in this postoperatively, the increase is not great enough to be significant. The standard error of the preoperative point is $386.7 \mathrm{cc}$. On the ninth day after operation when the curve has risen to its peak, the standard error is $317.4 \mathrm{cc}$. The actual difference between the averages of the two points is $804 \pm 500 \mathrm{cc}$. This is not a significant change in the mean of minute volume of air breathed. It is interesting to observe that all the other factors concerned in the respiration which were studied here showed significant changes. Though the respiratory system is nearer "decompensation" after operation than it was before, we did not demonstrate that the minute volume was significantly changed.

Rapid, shallow respiration is seemingly inefficient for the reason that ventilation of the dead space apparently accomplishes nothing. The tidal air is shown to be reduced in Figure 2. The volume of the dead space made up by the mouth, larynx, trachea, and primary bronchi remains the same but in relation to the smaller volume of tidal air is relatively increased; therefore rapid, shallow respiration seems inefficient due to the effort wasted in sweeping air through the relatively increased dead space. As an end result of this condition the diffusing surface of the lungs receives tidal air which contains a lower percentage of oxygen than before operation due to dilution with the stagnant air of the relatively increased dead space, and one factor in postoperative tachypnea seems therefore evident.

Next it was desirable to get information as to whether the muscles of forced inspiration were crippled more than those of forced expiration. Complemental and supplemental airs by definition measure the action of those two sets of muscles.

Cunningham (13) lists the following as vital to each phase of respiration: during inspiration, the thoracic cage is enlarged in all diameters. The anteroposterior and transverse diameters are increased by the elevation and forward movement of the sternum, elevation and eversion of the ribs, the vertical diameter by descent of the diaphragm. The ordinary muscles of inspiration are the diaphragm, intercostals, scalini, serrati posteriores, levatores costarum and subcostals. The extraordinary and accessory ones involved in forced inspiration, are the quadratus lumborum, 
pectorales, serratus anterior, sternomastoid, latissimus dorsi, infrahyoid, and extensors of the vertebral column.

Forced expiration is accomplished by the elasticity of the lungs, weight of the chest wall, elevation of the diaphragm, transversus thoracis, possibly the interosseous fibers of the internal intercostal muscles as rib depressors, and the muscles of the abdominal wall.

The degree of crippling after operation of the two sets of muscles is about the same; this is evident from Figure 3, based on 968 values. If

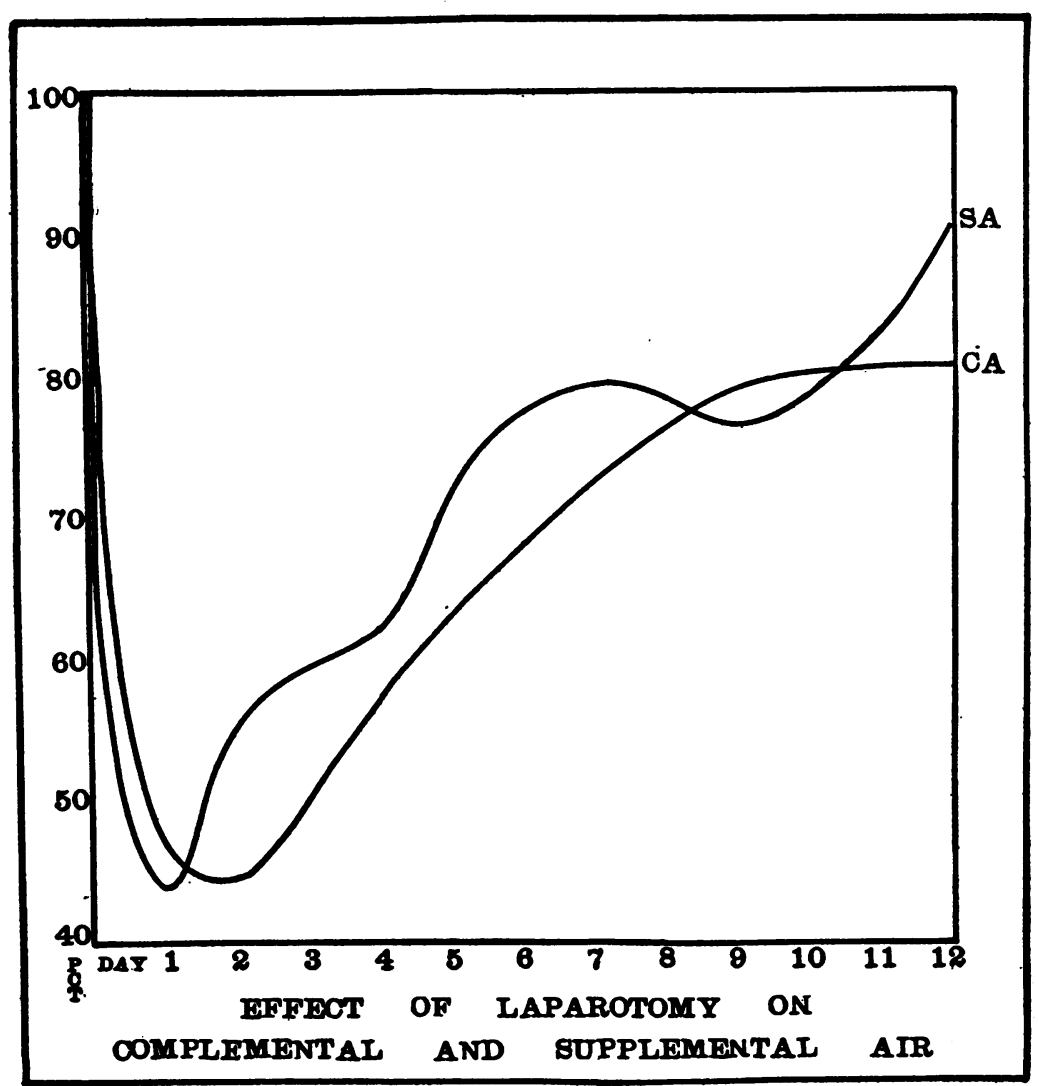

FIG. 3

$S A=$ Supplemental air

$C A=$ Complemental air

Abscissa $=$ Days postoperative

Ordinate $=$ Postoperative per cent of preoperative values

there is a difference, the muscles of forced inspiration are crippled for a longer time.

Analyzing the data further, it was found in both sexes that there is a strikingly greater effect on complemental air following upper abdominal 
operations than after lower. In males, upper abdominal operations cause a 20 per cent greater reduction in the complemental air after the first day. The reduction is maintained quite steadily throughout convalescence. In females, it is $\mathbf{3 0}$ to $\mathbf{5 0}$ per cent greater after upper abdominal operations than after lower.

The effect of laparotomy on the supplemental air in men is also striking. After the first postoperative day, the upper abdominal operations cause a 25 per cent greater reduction in supplemental air than do lower. This is maintained throughout convalescence. In females, the difference is slight and inconstant.

In order to check the reliability of the postoperative decrease in complemental and supplemental air, the standard errors have been calculated. In both these cases this has been done as above, taking the preoperative period as one point and contrasting it with the point of the curve which showed the maximum change. For complemental air the standard error of the preoperative period is 94.6 , on the second day of convalescence 65.4. The difference between the actual averages is $946.0 \pm 115.0 \mathrm{cc}$; ; therefore the decrease is a significant one.

The standard errors for similar points on the supplemental air curve are $48.6 \mathrm{cc}$. and $25.3 \mathrm{cc}$. The difference between the actual averages found at the two points is $370.0 \pm 54.8 \mathrm{cc}$. The significance is evident.

The effect of laparotomy on the vital capacity was determined. This has been done previously, notably by Churchill and McNeil (12), who showed clearly that there is marked lowering of the vital capacity following abdominal operations, and that the degree of lowering is related to the operation involved. In this series the vital capacity is in addition correlated with the other factors listed at the beginning of this paper. A more complete study has been made, furthermore, of the first five postoperative days. Figure 4 (based on 661 values) presents the data obtained following upper abdominal operations in men $\left(M_{U}\right)$, following lower abdominal operations in men $(M)$ and a curve representing composite data obtained in both men and women $(M F)$. From this larger series it is evident that the vital capacity does not recover as abruptly as had previously seemed the case.

Further consideration showed that the greatest reduction in vital capacity followed upper abdominal operations in men. On the first day after operation there was a 58 per cent reduction following upper abdominal operations, but only a 38 per cent reduction following the lower. This striking difference was maintained throughout convalescence. In women there is an insignificant difference between upper and lower operations, the reductions being 49 and 43 per cent respectively. Recovery was slower following upper abdominal operations in women than after lower; from the fourth to the twelfth day the difference increased from 8 to 25 per cent.

In the light of the three to one greater incidence of postoperative pul- 
monary complications in men than in women, the following is of interest. After upper abdominal operations in women, the greatest and most rapid rate of recovery of the vital capacity takes place very definitely between the second and fourth days while in males this is delayed and takes place between the fourth and sixth days.

The significance of the postoperative fall in vital capacity is apparent

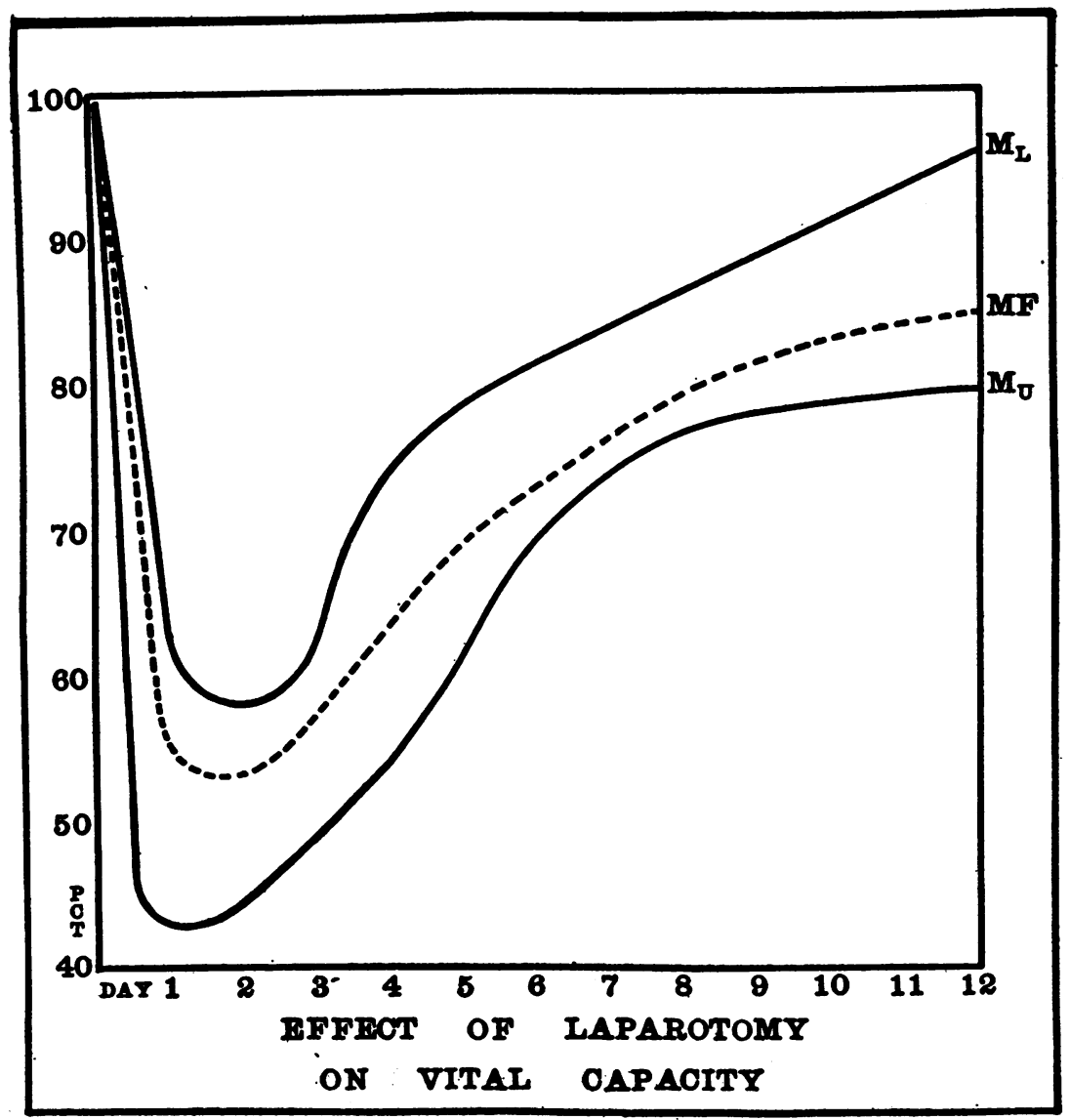

Fig. 4

$M_{\sigma}=$ Vital capacity in men following upper abdominal operations $M_{L}=$ Vital capacity in men following lower abdominal operations $M F=$ Vital capacity of both men and women; a composite of all data Abscissa $=$ Days postoperative

Ordinate $=$ Postoperative per cent of preoperative values

from calculating the standard error for the control period, which is 134.0 cc., and that on the second day postoperatively when it is $82.5 \mathrm{cc}$. The actual variation between the two points is $1380 \pm 157.3 \mathrm{cc}$. 
A study of the effect of laparotomy on the vital capacity offers interesting material for speculation as to what goes on in the respiratory apparatus of patients after operation, but due consideration must be given to certain factors entering into the changes observed. A consideration of how vital capacity is obtained should make this evident. The patient is required to take the deepest possible breath and then to expire as completely as possible. This procedure requires great cooperation on the part of normal persons while in the sick it demands more than can always be obtained. The desirability of using a method of study of the course of events in the chests of these patients which does not require their close cooperation is therefore apparent. Such a method is available in the study of lung volume. Vital capacity measurements as carried out here give interesting information as to the degree of injury to the respiratory mechanism, but it should be noted that vital capacity alone is not an index of actual lung volume. Studies of lung volume have been carried out along with those just described and the results will be discussed in a subsequent paper.

TABLE I

Summary of statistical data. Studies on 64 patients

\begin{tabular}{|c|c|c|c|c|c|c|c|}
\hline Curve & $\begin{array}{c}\text { Preoperative } \\
\text { average } \\
\text { control }\end{array}$ & $\begin{array}{c}\text { Stand- } \\
\text { ard error } \\
\text { control }\end{array}$ & $\begin{array}{c}\text { Postoperative } \\
\text { average } \\
\text { contrast }\end{array}$ & $\left|\begin{array}{c}\text { Stand- } \\
\text { ard error } \\
\text { contrast }\end{array}\right|$ & $\begin{array}{c}\text { Difference } \\
\text { between } \\
\text { average } \\
\text { control and } \\
\text { contrast }\end{array}$ & $\begin{array}{c}\text { Stand- } \\
\text { ard } \\
\text { error }\end{array}$ & $\begin{array}{l}\text { Signifi- } \\
\text { cant } \\
\text { change } \\
\text { shown }\end{array}$ \\
\hline $\begin{array}{l}\text { Respiratory rate, per } \\
\text { minute............ } \\
\text { Tidal air, } c c . . \ldots \ldots \\
\text { Minute volume, } c c . \\
\text { Complemental air, } c c \\
\text { Supplemental air, } c c . \\
\text { Vital capacity, } c c . .\end{array}$ & $\begin{array}{c}17.13 \\
614 \\
10,460 \\
1698 \\
632 \\
2851\end{array}$ & $\begin{array}{c}0.62 \\
23.6 \\
386.7 \\
94.6 \\
48.6 \\
134\end{array}$ & $\begin{array}{c}21.38^{1 *} \\
476^{1} \\
11,264^{9} \\
752^{2} \\
262^{2} \\
1471^{2}\end{array}$ & $\begin{array}{r}0.81 \\
19.4 \\
317.4 \\
65.4 \\
25.3 \\
82.5\end{array}$ & \begin{tabular}{rr}
\multicolumn{2}{c}{4.25} \\
138 & \pm \\
804 & \pm \\
946 & \pm \\
370 & \pm \\
1380 & \pm
\end{tabular} & $\begin{array}{c}1.02 \\
30.6 \\
500 \\
115 \\
54.8 \\
157.3\end{array}$ & $\begin{array}{l}\text { Yes } \\
\text { Yes } \\
\text { No } \\
\text { Yes } \\
\text { Yes } \\
\text { Yes }\end{array}$ \\
\hline
\end{tabular}

* These exponents indicate the postoperative day. The day chosen to contrast with the preoperative control period was the one showing the maximum deviation from the control.

\section{SUM MARY}

A method of analyzing the problem of the postoperative pulmonary complications is presented. This approach consisted in measuring the factors concerned in respiratory activity before and after operation. These were measured simultaneously. The factors were respiratory rate, tidal volume, total ventilation, complemental air, supplemental air and vital capacity. These values were determined for each patient preceding operation and then from day to day for two to three weeks following operation. The first five days afterward were studied the most intensely, since it is during this period that the majority of the postoperative pulmonary complications develop.

Standard errors are given to indicate the soundness of the data recorded. 


\section{CONCLUSIONS}

I. Laparotomy profoundly affects the respiration, producing:

1. Marked reduction in tidal air.

2. Marked increase in respiratory rate.

3. A slight but not significant change in total ventilation.

4. Rapid, shallow type of respiration which sets up a vicious cycle tending to increase further the respiratory rate.

5. Great reduction in complemental air, greater following upper than lower abdominal operations in both men and women.

6. Great reduction in supplemental air, greater following upper than lower abdominal operations in men but not in women.

7. About the same degree of crippling of the mechanism of forced inspiration and of forced expiration.

8. Great reduction in vital capacity, the greater crippling in both sexes following upper abdominal operations, and greater crippling in men than in women.

II. Comparatively small differences were found in the effects of the four groups of operations studied, yet there are large differences in the morbidity of the pulmonary complications in these four groups. There are undoubtedly many factors ${ }^{4}$ concerned in the etiology of the postoperative pulmonary complications which cannot be measured accurately. These other factors may require the postoperative changes brought out here to render them effective.

Note: The writer wishes to acknowledge his indebtedness to Dr. James H. Means and to Dr. Edward D. Churchill and to thank them for their counsel throughout the course of this work.

\section{BIBLIOGRAPHY}

1. Chevers, N., Guy's Hosp. Rep., 1843, i, 78. An Inquiry into Certain of the Causes of Death after Injuries and Surgical Operations in London Hospitals.

2. Franke, F., Verhandl. d. deutsch. Gesellsch. f. Chir. Berl., 1905, xxxiv, 117. Vierunddreissigster Congress (Discussion).

3. Cutler, E. C., and Morton, J. J., Surg., Gynec. and Obst., 1917, xxv, 621. Postoperative Pulmonary Complications.

4. Whipple, A. O., Surg., Gynec. and Obst., 1918, xxvi, 29. A Study of Postoperative Pneumonitis.

5. Cleveland, M., Surg., Gynec. and Obst., 1919, xxviii, 282. Further Studies in Postoperative Pneumonitis.

4 An important factor may be the condition of the patient who undergoes a given type of operation. For example, gastric surgery is followed by a very high incidence of postoperative pulmonary complications. Patients undergoing gastric surgery are frequently debilitated from vomiting, improper diet and the ill consequences of malignant tumors and ulcer. 
6. Mandl, F., Wien. klin. Wchnschr., 1921, xxxiv, 214. Zur Statistik der postoperativen Lungenkomplikationen und über erfolgreiche Bestrebungen zu deren Prophylaxe.

7. Cutler, E. C., and Hunt, A. M., Arch. Surg., 1920, i, 114. Postoperative Pulmonary Complications. Arch. Int. Med., 1922, xxix, 449. Postoperative Pulmonary Complications.

8. Elwyn, H., J. A. M. A., 1924, 1xxxii, 384. Postoperative Pneumonia.

9. Featherstone, H., Brit. J. Surg., 1924, xii, 487. An Inquiry into the Causation of Postoperative Pneumonia.

10. Coryllos, P. N., J. A. M. A., 1929, xciii, 98. Postoperative Apneumatosis (Atelectasis) and Postoperative Pneumonia.

Surg., Gynec. and Obst., 1930, 1, 795. Postoperative Pulmonary Complications and Bronchial Obstruction; Postoperative Bronchitis, Atelectasis (Apneumatosis) and Pneumonitis Considered as Phases of the Same Syndrome.

11. Kolodny, A., J. A. M. A., 1925, lxxxiv, 810. Pulmonary Complications After Laparotomies. The Site of Hypodermoclysis in Relation to Them.

12. Churchill, E. D., and McNeil, D., Surg., Gynec. and Obst., 1927, xliv, 483. The Reduction in Vital Capacity Following Operation.

13. Cunningham, D. J., Textbook of Anatomy. William Wood and Co., N. Y., 1915 , 4th ed., p. 474. 